\title{
El Museo de la Solidaridad de la Unidad Popular al exilio (1971-1991). Una experiencia transnacional en tiempo de guerra fría cultural
}

\section{The Museo de la Solidaridad from the Popular Unity to Exile (1971-1991). A Transnational Experience at a Time of Cultural Cold War}

\author{
Élodie Lebeau* \\ (D) https://orcid.org/0000-0002-3350-9706 \\ Université Toulouse 2 Jean Jaurès \\ Département histoire de l'art et archéologie \\ elodie.lebeau2@gmail.com
}

Resumen: Este artículo se propone presentar las redes transnacionales de solidaridad que permitieron la creación del Museo de la Solidaridad (1971-1973) durante la Unidad Popular y su desarrollo en el exilio a través del Museo Internacional de la Resistencia Salvador Allende (1975-1990), hasta su regreso a Chile en 1991. Analizando las interconexiones entre redes políticas, artísticas e intelectuales, nos proponemos destacar el papel central de las artes visuales en las manifestaciones de solidaridad con Chile durante el gobierno

* Doctoranda en historia e historia del arte, Universidad Toulouse 2 Jean-Jaurès, Francia; Pontificia Universidad Católica de Chile, Santiago de Chile; miembro científico de la Casa de Velázquez, Madrid (2019-2020).

cómo citAr: Lebeau, É. (2020). El Museo de la Solidaridad de la Unidad Popular al exilio (1971-1991). Una experiencia transnacional en tiempo de guerra fría cultural. Secuencia (108), e1835. DoI: https://doi. org/10.18234/secuencia.v0i108.1835

c) $(1)$ Esta obra está protegida bajo una Licencia Creative Commons Atribución-NoComercial 4.0 Internacional. 
de Salvador Allende y, luego, contra la dictadura del general Pinochet. Enfocándose en los niveles locales, nacionales e internacionales, esta contribución privilegia el diálogo entre varias escalas geográficas y temporales y distintos enfoques disciplinarios. Se interesa a la vez en los discursos y estrategias de los agentes y de las instituciones participantes, incluso los de los artistas mediante el análisis de los imaginarios que emergen de las obras.

Palabras clave: Museo de la Solidaridad; Unidad Popular (1970-1973); solidaridad internacional; redes artísticas; América Latina.

Abstract: This article seeks to present the transnational solidarity networks that allowed the creation of the Museo de la Solidaridad (1971-1973) during the Popular Unity and its development in exile through Museo Internacional de la Resistencia Salvador Allende (1975-1990) until its return to Chile in 1991. Analyzing the interconnections between political, artistic and intellectual networks, we set out to highlight the central role of the visual arts in the manifestations of solidarity with Chile during the government of Salvador Allende and subsequently against the dictatorship of General Pinochet. Focusing on the local, national, and international levels, this contribution examines the dialogue between various geographical and time scales and disciplinary approaches. At the same time, it explores the discourses and strategies of the participating agents and institutions, including those of artists through the analysis of the imaginaries that emerge from their works.

Key words: Museo de la Solidaridad; Popular Unity (1970-1973); international solidarity; artistic networks; Latin America.

Recibido: 3 de marzo de 2020 Aceptado: 13 de julio de 2020

Publicado: 4 de noviembre de 2020

\section{INTRODUCCIÓN}

$\mathrm{E}_{\text {ganizó en Santiago de Chile un encuentro de intelectuales, periodistas }}^{\mathrm{n} \text { abril de 1971, mientras explaba el caso Padilla en La Habana, se or- }}$ 
y artistas venidos del mundo entero para constatar los primeros avances del gobierno socialista de Salvador Allende y promoverlos en sus países de origen. De esta "Operación Verdad” surgió la idea de José María Moreno Galván, crítico de arte español, de pedir a los artistas del mundo una obra para apoyar simbólicamente al proceso político chileno (Zaldívar, 1991, pp. 12-13). Progresivamente, esta idea maduró y tomó una orientación más institucional. Se formó un Comité Internacional de Solidaridad Artística con Chile (CISAC), con personalidades relevantes de la museología y la crítica de arte a nivel mundial, que se dedicó a solicitar su obra a los artistas en varios países. El éxito rápido de la iniciativa llevó a Mário Pedrosa, crítico de arte brasilero exiliado en Chile y director del CISAC, a concebir un museo de arte moderno representativo del proceso revolucionario. Inaugurado parcialmente en Santiago, el 17 de mayo de 1972, con las primeras donaciones (Miranda, 2013), el Museo de la Solidaridad conoció varias peripecias a lo largo de su historia. Del Chile socialista, al exilio, y hasta su retorno, presentaremos su odisea que constituye una experiencia transnacional de solidaridad inédita mezclando arte y política.

Nuestro estudio se inscribe en una renovación epistemológica y metodológica de los estudios de la guerra fría que busca poner de relieve su dimensión cultural y el papel de los países pertenecientes entonces al "tercer mundo". Esta historiografía reciente (McMahon, 2013; Westad, 2017), que rompe con la tradición dicotómica dominante con respecto a este conflicto, nos ofreció herramientas adecuadas para analizar la dimensión transnacional de este museo, poniendo el enfoque sobre las redes múltiples y los fenómenos complejos inter y extraestatales que van más allá de la historia de las relaciones internacionales habituales. Como lo destaca el historiador Rafael Pedemonte (2012), esta perspectiva interdisciplinaria nos lleva inevitablemente a reactivar los "paradigmas ideológicos" (p. 138) que sustentaron los programas culturales desarrollados por las dos grandes potencias a destinación de los países del "Sur" como los que permitieron que surgieran discursos y prácticas alternativos desde los países no alineados. Estos paradigmas son los que guiaron los compromisos de los agentes que nos interesan en una época en que se enfrentaban no dos, sino varios modelos y proyectos políticos, en la encrucijada entre aspiraciones universales y preocupaciones nacionales, regionales o locales. El estudio de los intercambios culturales es entonces indispensable para aprehender la especificidad de este conflicto y analizar los mecanismos de propaganda desarrollados por los diferentes agentes, a nivel 
individual como institucional (Pedemonte, 2012, p. 139). Retomamos el concepto de "Guerra Fría cultural" (Stonor Saunders, 2013) para describir las estrategias sutiles de soft power empleadas entonces en los medios culturales por organizaciones o Estados, destinadas a promover ciertas visiones del mundo y a defender intereses políticos y económicos particulares.

Esta dimensión político-cultural del conflicto (Shaw, 2001) ha llevado a los investigadores a interesarse, en esta ultima década, por los aportes artísticos de la solidaridad internacional y, sobre todo, por los museos y exposiciones "en el exilio", objetos privilegiados para explorar las interacciones entre arte y política (Khouri y Salti, 2018). Anteriormente, la solidaridad internacional había sido estudiada por disciplinas como la historia, el derecho o la sociología (Devin, 2004; Stites Mor, 2013), dando poco o ningún espacio a la contribución de los artistas y de los agentes culturales. De este modo, nuestro estudio forma parte de una historiografía reciente de los movimientos de solidaridad que ambiciona revelar la significativa contribución de las artes, y principalmente de las artes visuales, en las manifestaciones de solidaridad (Piškur, 2016).

En este conflicto global donde los países y actores del "tercer mundo" desempeñaron un papel central (Westad, 2007), el Chile de la Unidad Popular (1970-1973) se destacó por un aporte político inédito y paradigmático encarnado en su vía pacífica al socialismo que canalizó la última gran esperanza mientras Cuba entraba en su fase de sovietización. La diplomacia multilateral, como la apertura democrática promovida por el gobierno de Salvador Allende, ofrecía posibilidades de desarrollo de contramodelos culturales en los cuales podían encontrarse varios actores de diferentes orígenes políticos y espaciales, desde los países socialistas de Europa del Este hasta el nacionalismo mexicano, pasando por la socialdemocracia sueca. Los estudios sobre el exilio chileno (Camacho Padilla, 2011; Montupil Inaipil, 1993; Prognon, 2013b; Rojas Mira, 2013; Rojas Mira y Santoni, 2013; Wright y Oñate Zúñiga, 2007), y más generalmente sobre la recepción de la Unidad Popular en el exterior de Chile, pre y postgolpe de Estado, vienen a desafiar las historias nacionales tradicionales enfocándose sobre las relaciones y conexiones existentes entre esta experiencia política global (Fermandois, 1985; Harmer y Riquelme Segovia, 2014) y la especificidad de cada contexto nacional.

Sin embargo, hasta el momento, pocos trabajos se han interesado en los aspectos culturales de la solidaridad con Chile (Norambuena, 2008; Prognon, 2013a) entendidos como estrategias de soft power. La perspectiva multinivel 
(Levi, 2018) y el diálogo entre varios enfoques epistemológicos de la nueva historia del arte (Barreiro López, 2019; Joyeux-Prunel, 2017), junto a los de la historia de las ideas y de la historia de las relaciones internacionales (Iriye, 1991) son herramientas privilegiadas para analizar la compleja experiencia del Museo de la Solidaridad desde su creación hasta hoy. Este método interdisciplinario permite enfocarse en el papel decisivo de los actores como "intermediarios", "go-betweens" (Saunier, 2013, p. 57), pero también para analizar las intersecciones entre arte y política, en las relaciones internacionales que marcaron la experiencia de la Unidad Popular (UP), en Chile y en el exilio.

¿Cuáles fueron los modelos, las redes de actores y los discursos que favorecieron el desarrollo del Museo de la Solidaridad y sus actividades tanto al interior como al exterior de Chile? A partir de un trabajo que conjuga lecturas de obras de referencia, reunión de campos historiográficos diversos, entrevistas con actores y escrutinio de archivos, nos interesaremos por el significado de un museo transnacional en tiempos de guerra fría cultural.

\section{EL MUSEO DE LA SOLIDARIDAD (1971-1973). UN CONTRA-MODELO CULTURAL TRANSNACIONAL}

Como lo nota Joaquín Fermandois (1985, p. 15) en su libro Chile y el mundo, 1970-1973, la historia de las relaciones internacionales ya no puede ser exclusivamente sinónimo de historia diplomática. El caso del Museo de la Solidaridad es, en este sentido, muy representativo de la importancia que la cultura puede desempeñar en la diplomacia de un Estado (Sirinelli, 2004). Ahora presentaremos los desafíos de este museo y las condiciones prácticas de su desarrollo en Chile durante la UP.

La emergencia de un proyecto de "museo de arte moderno y experimental" en Chile interviene en un contexto artístico continental marcado por la hegemonía del mercado estadunidense. En los años setenta, la División de Artes visuales del Departamento de Asuntos Culturales de la Organización de los Estados Americanos (OEA), era entonces para los artistas un intermedio inevitable para calar en el mercado del arte latinoamericano y tener una ventana abierta hacia la escena artística occidental. Esta institución mediadora entre las inversiones estadunidenses en América Latina y los artistas en la región apoyaba una política destinada a luchar, a través de la promoción del expresionismo abstracto, contra el arte comprometido y la influencia de la 
Escuela Mexicana de Pintura heredada del muralismo de los años 1920 (Fox, 2016). De la misma manera que las actividades del Congreso por la Libertad de la Cultura (1959-1969) eran financiadas por parte de la CIA (Stonor Saunders, 2013), los programas artísticos de la oEA no dejaban ninguna duda en cuanto al rol de apalancamiento de la cultura en las relaciones exteriores en tiempos de la guerra fría (Shaw, 2001). La "ciudadanía hemisférica" defendida por el crítico de arte José Gómez Sicre, director del Departamento de Artes Visuales de la oEA entre 1948 y 1976, promovía una comunidad afectiva transnacional posibilitada por la privatización del sector de la cultura y opuesta al control directo de los gobiernos en el arte.

En los años de post segunda guerra mundial, no existía todavía una escena continental alternativa al modelo panamericano orientado a favorecer la creación y movilidad de los artistas de América Latina. A partir de la revolución cubana, varias instituciones se abocaron a explorar y definir la identidad latinoamericana para favorecer, según las palabras de Miguel Rojas Mix, "una conciencia del destino común compartido entre los pueblos (del) continente" (Macchiavello y Suárez, 2015, p. 175). Esto traía consigo una nueva concepción de lo que debería ser el arte revolucionario, frente a la implantación de procesos socialistas en la región. Así, no se trataba solamente de oponerse al modelo estadunidense y a su escena y mercado del arte, sino de crear nuevas infraestructuras cuyos pilares serían no mercantiles, además de configurar un nuevo modelo de cooperación internacional inscrito en una visión del mundo no capitalista. Contrariamente al modelo mercantil y liberal desarrollado por Sicre, el gobierno cubano y la UP chilena querían poner las políticas públicas al servicio de la democratización de la creación y del acceso al arte (Unidad Popular, 1970, pp. 27-32). Cuando Salvador Allende fue elegido presidente de la república, se restablecieron las relaciones diplomáticas entre los dos países y Cuba pudo tener un aliado en el subcontinente (Harmer, 2011). Se generó entonces un "meridiano de la solidaridad" tanto político como artístico (Macchiavello y Suárez, 2015, p. 177), facilitado por la apertura de una vía aérea Santiago-La Habana.

La creación de la Casa de las Américas en La Habana en el primer año de la revolución, como las actividades del Instituto de Arte Latinoamericano (IAL) en Chile durante el gobierno de Salvador Allende, deben entenderse como dos polos generadores de un programa cultural de proyección continental que dio inicio a nuevas formas de compromiso artístico (Macchiavello y Suárez, 2015, p. 205). La Exposición de La Habana (Bienal Chile-Cuba) 
organizada conjuntamente por el IAL y la Casa de las Américas en julio de 1971, fue la ocasión de intercambiar colecciones de obras entre los dos países. Las obras cubanas integraron el Museo de la Solidaridad, mientras que las de Chile se incorporaron a la Galería de Arte Latinoamericano de la Casa de las Américas. La declaración de Miguel Rojas Mix y Adelaida de Juan (1971) en cuanto a la significación de este evento resume perfectamente el otro modelo sociocultural que defendían estos dos gobiernos de orientación revolucionaria, tanto para su propio país como para el conjunto de América Latina:

Por primera vez en la historia de América Latina se unen dos países para realizar una exposición en que se donan recíprocamente las obras. [...] Tiene, a nuestro juicio, una significación muy grande para el proceso de desalineación del artista y para entender el aporte que él puede hacer a la cultura latinoamericana. El artista que trabaja para el mercado transforma su obra en un valor de cambio y trabaja para mantener el status de la burguesía capaz de adquirir estos bienes. En cambio, aquí, el artista trabaja directamente para el pueblo; pues su obra esta destinada a incorporarse al acervo público de dos países, ambos desposeídos de riqueza artística. Plantea asimismo este encuentro otra realidad: la pobreza cultural latinoamericana debido a la falta de poder adquisitivo que tienen todos nuestros países para obtener bienes culturales. Sin duda, que ninguno de nosotros está en condiciones económicas de adquirir una colección como sería necesario para formar un gran museo. Con acciones de este tipo, en cambio, podemos comenzar en diversas partes de la América Latina a concentrar obras y a utilizarlas como elementos formadores de la capacidad artística de las masas (p. 187).

Esta declaración contiene una crítica marxista implícita de la dependencia económica y cultural respecto a Estados Unidos, a la cual opone una visión optimista del artista emancipado del mercado y comprometido con las causas del pueblo. Todas estas iniciativas artísticas tienen que ser entendidas entonces como focos de una lucha multidimensional más amplia, socialista y tercermundista, que ambiciona inclinar la balanza del poder a nivel global.

En tres años de gobierno, la up logró convertirse en un centro nodal de los movimientos de liberación nacional y social del mundo. La atracción de su modelo venía primero de su carácter inédito y democrático. Igualmente, cabe destacar que la experiencia chilena se inscribía en un proceso de "transnacionalización” de la convivencia mundial (Fermandois, 1985, p. 71.), ali- 
mentada entre otros por los encuentros tricontinentales (Bouamama, 2016; Malher, 2018;) y las redes de actores transatlánticas de intelectuales y artistas militantes (Barreiro López, 2019). Interesarse en la génesis del proyecto del Museo de la Solidaridad y su corta existencia entre 1971 y 1973 nos lleva a destacar tres niveles de análisis en las relaciones exteriores de esta coalición política: uno diplomático, uno institucional y uno vinculado al papel de los agentes independientes.

Primeramente, el Museo de la Solidaridad pudo desarrollarse gracias a la diplomacia multilateral del gobierno de la up. Como país del llamado "tercer mundo" y fuertemente dependiente de la financiación exterior, el Chile de Allende se esforzó por construir alianzas muy diversas destinadas a independizarse en el concierto internacional de las naciones (Harmer, 2011). Sin cerrarse a la cooperación con Estados Unidos, Chile desplegó un ejercicio diplomático estratégico con el objetivo de cambiar el equilibrio de poder en la región. Los historiadores Claudia Rojas Mira y Alessandro Santoni (2013) destacan tres grandes polos de amistad política: la izquierda europea plural, los países tercermundistas y los "compañeros" del bloque socialista.

En un contexto de conflicto mundial, y particularmente de "guerra fría interamericana" (Harmer, 2011, p. 1), las políticas de desarrollo regional socioeconómicas y culturales de Estados Unidos hacia América Latina, implementadas a través de programas como la Alianza para el Progreso, organismos como la Unión Panamericana (UPA) y fundaciones corporativistas (Ford o Rockefeller, por ejemplo), fueron fuertemente criticadas por los movimientos nacionalistas, socialistas y comunistas que veían en ellos instrumentos neocoloniales e imperialistas. La Tercera Conferencia de las Naciones Unidas sobre Comercio y Desarrollo (UNCTAD III), organizada en Santiago de Chile del 13 de abril al 21 de mayo de 1972, es paradigmática de esta condena internacional en contra de la dependencia de los países tercermundistas hacia los países del "Norte". El presidente de la república mexicana, Luis Echeverría, pronunció un discurso donde llamaba a una batalla mundial por el desarrollo y presentó un proyecto de "Carta de Derechos y Deberes Económicos de los Estados" (Castaneda, 1974, p. 33). El documento se proponía combatir el subdesarrollo injusto de los países del Tercer Mundo y promover un código universal de cooperación entre los Estados que respetara la libre determinación de los pueblos.

El Museo de la Solidaridad fue inaugurado durante este encuentro internacional, el 17 de mayo de 1972. En una carta destinada a José María 
Moreno Galván, Salvador Allende le indica que "sería muy significativo que pudiéramos inaugurar su proyectado Museo de Arte Moderno en el curso de esa Conferencia. Constituiría una demostración de solidaridad de los artistas progresistas de todo el mundo hacia nuestro proceso político" ${ }^{1}$. Este hecho demuestra que constituía un aspecto realmente primordial de la diplomacia cultural de la up. Además, los archivos revelan el papel central de las embajadas en la colección de las obras del Museo en cada país y sus envíos a Chile. Los funcionarios de las embajadas estaban muy al corriente del proyecto y se presentaban como referentes privilegiados para guiar a los artistas o a todas las personas que querían participar. En una carta a un destinatario desconocido, Mário Pedrosa lo invita a contactar a Raquel Bunster, esposa del embajador chileno en Londres -Álvaro Bunster- para tener más informaciones, ${ }^{2}$ además de comentarle el rol de Pablo Neruda, entonces embajador de Chile en Francia, en la visibilización de la iniciativa en Europa. Efectivamente, en los Archivos del Ministerio de Asuntos Exteriores de Chile se encuentran documentos que dan fe de la energía que puso el poeta en la colección y envío de las obras del comité francés ${ }^{3}$. En Estados Unidos, la crítica de arte Dore Ashton, que se encargó de la selección de los artistas estadunidenses, también tuvo que ponerse en contacto con el embajador de Chile en Washington, Orlando Letelier, para gestionar los trámites de las obras entre estos dos países.

En cuanto a la función de las instituciones nacionales independientes del poder pero vinculadas a él en el sentido que acompañaban de manera evidente al proceso socialista, hay que subrayar el papel central del Instituto de Arte Latinoamericano (IAL), dirigido por Miguel Rojas Mix, la Facultad de Artes de la Universidad de Chile, cuyo decano era el pintor catalán José Balmes, naturalizado chileno en 1947, y el Museo de Arte Contemporáneo, dirigido por Guillermo Núñez (1971-1972) y luego Lautaro Labbé (1972-1973). El Museo de la Solidaridad también aprovechó una amplia red institucional a nivel internacional para desarrollarse. Dos ejemplos destacables son la Casa

${ }^{1}$ Carta del presidente de la República de Chile, Salvador Allende, a José María Moreno Galván. 11 de agosto de 1971. Arch. MG 19176422 CDB 176536. Biblioteca Museo Nacional Centro de Arte Reina Sofía, Madrid.

${ }^{2}$ Carta de Mário Pedrosa a destinatario desconocido. S. f. [1972]. Fondo SOL.ADM. A010. s0017. Archivo Museo de la Solidaridad Salvador Allende (en adelante MSSA), Santiago de Chile.

${ }^{3}$ Carta de Pablo Neruda, embajador de Chile, al señor ministro de Relaciones Exteriores. 6 de abril de 1972. Fondo Países. Embajada de Francia. Oficios Ord. T. II. No. 551/205. Archivo Histórico General de Chile (en adelante AHG), Santiago de Chile. 
de las Américas en La Habana, a través de Mariano Rodríguez, entonces subdirector de esta institución, y el Instituto Nacional de Bellas Artes en México, por medio de la figura de Fernando Gamboa (Garza y Vargas Santiago, 2016).

A niveles individuales, los agentes móviles también generaron redes internacionales que favorecieron la recopilación de obras para enriquecer las colecciones del museo. El Comité Internacional de Solidaridad Artística con Chile (CISAC), creado en 1971 a continuación de la "Operación Verdad" para poner en marcha el proyecto de recolección de obras, estaba profundamente vinculado a las redes de la Asociación Internacional de Críticos de Arte (AICA). Entre otros, el crítico de arte brasilero Mário Pedrosa, quien era vicepresidente de la AICA, fue nombrado presidente del comité mientras que el crítico de arte italiano, Giulio Carlo Argan, ${ }^{4}$ miembro del cISAC, era en ese momento presidente de la AICA (Yasky y Zaldívar, 2018, pp. 300-301). Ayudado por los otros miembros del comité, Mário Pedrosa se puso en contacto con muchas personalidades del mundo del arte global para promover la iniciativa a nivel internacional. Los intercambios de cartas ilustran la puesta en marcha de redes en la construcción de un proyecto museal y la proximidad o la amistad existente entre los protagonistas.

El proyecto del Museo de la Solidaridad debe ser visto como uno de los resultados en las artes del proyecto socialista y de la diplomacia del gobierno de la Unidad Popular, pero también como un intento institucional de generar redes artísticas alternativas a nivel continental y transatlántico. Su estudio subraya la tensión existente entre las estructuras transnacionales, la trayectoria individual de agentes heterogéneos (Barreiro López, 2019, p. 26), así como las instituciones y las sucursales del poder estatal.

\section{UN MUSEO "EN EL EXILIO". EL MUSEO INTERNACIONAL DE LA RESISTENCIA SALVADOR ALLENDE (1975-1990)}

El golpe de Estado provocó un gran shock en la comunidad internacional (Compagnon y Moine, 2015). Las redes precedentemente constituidas en solidaridad al gobierno de la Unidad Popular no tardaron en ponerse al servicio

${ }^{4}$ Luego, Giulio Carlo Argan fue elegido alcalde de Roma, en la lista del Partido Comunista Italiano, en 1976. 
de la acogida del exilio chileno y de las denuncias de los crímenes de la Junta militar. Después de haber intentado recuperar las obras de las manos del gobierno autoritario, sin éxito, en 1975 se tomó la decisión de recrear el museo en el exilio, dándole un nuevo nombre -Museo Internacional de la Resistencia Salvador Allende (MIRSA)-, para apoyar una campaña en las artes contra la dictadura. La presencia multicontinental de este museo nos invita a adoptar un análisis multinivel para comprender tanto los contextos nacionales que acogieron a sus comités como la dimensión y las implicaciones transnacionales de este museo (véase mapa 1 ).

La acogida del MIRsA en una decena de países del mundo, a través de simples exposiciones temporales o de la creación de comités nacionales permanentes, más de dos años después del golpe de Estado, se explica a su vez por la implantación global de la diáspora chilena como por los contextos políticos y culturales favorables (Lebeau, 2018). Presente a la vez en América Latina, Europa Occidental, Europa del Este, y hasta en África (Argelia), el MIRSA se apoyó para implantarse en las redes de solidaridad preexistentes al exilio en los medios políticos, intelectuales y artísticos. Esas redes se pusieron en marcha para gestionar de la mejor manera posible la llegada de los flujos de chilenos refugiados en las embajadas y consulados, y buscarles trabajo y vivienda, así como para promover las iniciativas de la resistencia en el exterior.

El exilio trae igualmente una redefinición de las prerrogativas del museo. Al añadir el nombre del presidente fallecido, el museo se inscribe en la continuidad del proyecto democrático y socialista de Salvador Allende, mientras se unía a la resistencia contra el régimen usurpador en el exterior. Compuesto por un secretariado permanente dirigido por Miria Contreras, secretaria e íntima amiga del "compañero-presidente", su tarea era reunir obras de arte donadas por los artistas solidarios con la resistencia chilena con el fin de organizar exposiciones y "ser un instrumento político de agitación y propaganda" ${ }^{5}$.

La dimensión realmente inédita del MIRSA fue su presencia transnacional que, luego, inspiró a otras iniciativas de solidaridad como el proyecto de un museo de solidaridad para el pueblo palestino (Khouri y Salti, 2018). El museo funcionó por medio de exposiciones itinerantes dentro de los países o a veces transfronterizas. Por ejemplo, una parte de la colección francesa fue

\footnotetext{
${ }^{5}$ Informe de Miria Contreras sobre el origen y propósito del MIRSA. s. f. [1975]. Fondo RES.ADM. B010. Doc. a0002. MSSA, Santiago de Chile.
} 


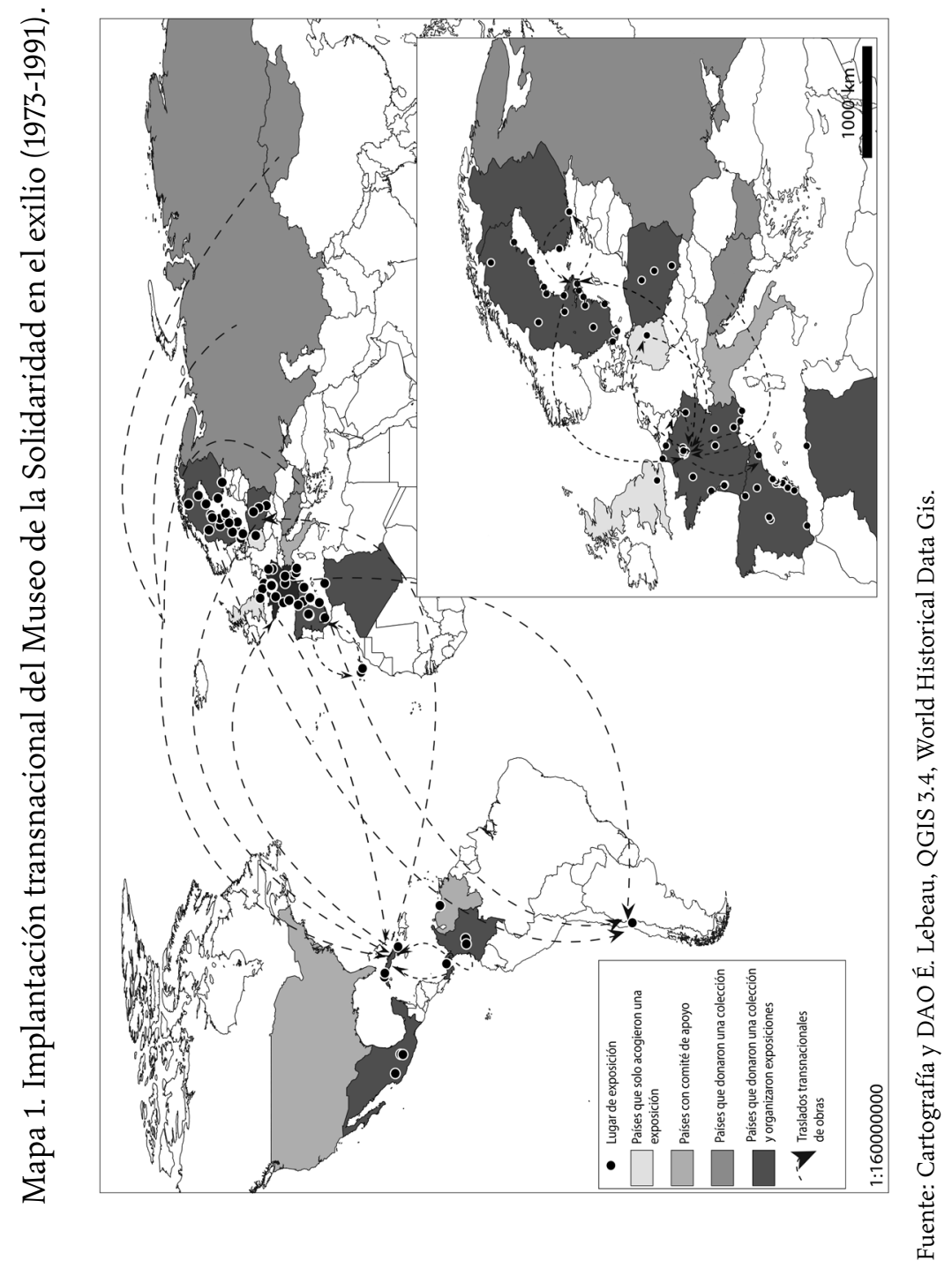


expuesta en Berlín Oeste (Festival Horizonte '82, del 29 de mayo al 20 de junio 1982) y en Luxemburgo, del 21 de marzo al 20 de mayo de 1986. Como se puede notar en el mapa, algunas colecciones como las de Bulgaria, de Mongolia o de la Unión Soviética fueron trasladadas a países -Cuba, en estos casos- que pudieron gestionar el almacén y las exposiciones de las obras.

El MIRSA se aprovechó del diálogo fructífero con otras realidades políticas y artísticas a niveles nacionales. Esta dislocación geográfica trajo consigo una multiplicación de prácticas en torno al museo, ya que los distintos comités se organizaron de un modo independiente y sus formas de funcionamiento dependieron de la situación local y nacional en la que se encontraban. Así, los recursos humanos, financieros y materiales puestos a disposición del museo por partidos o personalidades políticas, sindicatos o instituciones no pueden compararse de un país a otro (Lebeau, 2018, pp. 226-229). Dada la aparente autonomía de los comités, Carla Macchiavello (2017) favorece el concepto de "Museos de la Resistencia", ya usado por los protagonistas de la época, que pone de relieve la diversidad que caracteriza a las colecciones, actores o actividades de esta institución en el exilio (p. 28).

Mayoritariamente, estos países fueron los que tenían relaciones diplomáticas bastante fuertes con el gobierno de Salvador Allende. En los países del Este, cabe destacar que las acciones solidarias con Chile eran medidas y gestionadas por las autoridades del Estado (Preda, 2020). Si en Francia, la organización era un poco improvisada, la burocracia de los Estados bajo influencia soviética aseguraba una administración ordenada y un discurso claro en torno a la recolección de obras y sus exposiciones. Las investigaciones de Matul (2018) tienden a mostrar que las donaciones de los artistas polacos no se pueden interpretar como un gesto espontáneo, sino como una decisión de las autoridades polacas de colaborar con el MIRSA tras la visita de "la compañera” Miria Contreras a Polonia en abril 1977 (p. 213). En este caso, el director del Museo Sztuki de Łódz, Ryszard Stanisławski, actuó como intermedio entre el MIRSA, las autoridades polacas -en particular el Ministro de Cultura y Arte- y los artistas. Su tarea era solicitar la participación de los artistas y organizar la exposición que se presentó en el Museo Sztuki antes de ser mandado a Cuba donde fueron expuestas en la Galería Centro de Arte Internacional de Ciudad de La Habana, en diciembre de 1978.

Cuando no se trataba de una proximidad ideológica o estratégica con la UP al nivel gubernamental, la acogida de los exiliados se explicó por la influencia de algunos partidos políticos, comunistas, socialistas o socialdemó- 
cratas que habían accedido al poder a nivel local y/o, además de tener los medios financieros suficientes, eran mediáticamente visibles a nivel nacional. Los comités contaron entonces con la ayuda de partidos políticos o grupos sindicales que, incluso más allá de las actividades del museo, proporcionaron almacenes para preservar las obras o contribuyeron a costear los gastos financieros necesarios para mover las obras, incluido su traslado final a Chile. Por ejemplo, en Francia, una parte de la colección del museo fue guardada, durante los años ochenta, en las bodegas de un edificio municipal en Bondy, ciudad en los suburbios de París entonces gobernada por un alcalde socialista, Claude Fuzier (Lebeau, 2016, pp. 48-50).

En general, las inauguraciones de estas exposiciones fueron utilizadas como un teatro de representación para las personalidades políticas nacionales. En Francia, François Mitterrand pronunció un discurso donde se comprometió, si era elegido presidente de la república francesa, a romper las relaciones diplomáticas con el Chile de Augusto Pinochet. ${ }^{6}$ Las exposiciones del MIRSA eran también entonces una ocasión para la realización de encuentros políticos entre los representantes del gobierno de la Unidad Popular en el exilio y sus aliados. En México, la inauguración de una exposición del MIRSA en el Museo de Arte Moderno, el 17 de junio de 1977, fue marcada por la presencia del nuevo presente de la república, José López Portillo, y de personalidades chilenas en el exilio como Hortensia Bussi, Isabel Allende, respectivamente viuda e hija de Salvador Allende, y Luis Corvalán, secretario general del Partido Comunista de Chile, recientemente liberado de las prisiones militares.

Sin embargo, las redes involucradas no eran solamente partidistas. Los mundos de los artes también se comprometieron en las actividades de la resistencia, reactivando las redes conformadas durante el gobierno de la Unidad Popular a través del CISAC o del IAL, principalmente. En el caso de los artistas y trabajadores culturales, hay un ejemplo relevante de esta resignificación de las redes de solidaridad transnacionales. En noviembre de 1973, algunos días después de haber recibido en el Museo de Artes Decorativas de París una delegación de artistas chilenos exiliados, la sección francesa de la Asociación Internacional de Críticos de Arte (AICA) publicó una declaración, donde pedía "la restitución a todos los donantes de las obras mandadas al Museo de la Solidaridad". Se mostraba preocupada por "la situación de los

${ }^{6}$ Jean-Pierre Clerc. Au Festival Latino-américain de Nancy / M. Mitterrand : si le parti socialiste arrive au pouvoir il rompra avec le Chili, Le Monde, 7 de mayo de 1977. 
artistas chilenos ya refugiados en Francia" o que llegaran después, especificando que: "Necesitan subsidios y talleres para trabajar hasta que puedan encontrar trabajo, becas, oficios de profesores. La AICA-Francia pide a todos sus miembros informar lo que puedan hacer en su favor."7

De igual forma, algunos comités del museo estuvieron dirigidos por directores y/o conservadores de museos de arte. En estos casos, se hizo una selección de obras con el fin de preservar sólo aquellas con un interés plástico real. En el caso de Suecia, por ejemplo, el papel de figuras prominentes del mundo del arte nacional, como Björn Springfelt, Monica Nieckels y Sonja Martinson Uppman, fue crucial para crear una colección y organizar exposiciones. Lo mismo sucedió en Colombia con el compromiso de Marta Traba, directora del Museo de Arte Moderno de Bogotá; en México, con Fernando Gamboa, director del Museo de Arte Moderno de México, y en Polonia, con Ryszard Stanisławski, director del Museo Sztuki. En todos estos países, las obras fueron seleccionadas y conservadas durante un periodo por instituciones oficiales de arte.

Destacar el papel de las instituciones políticas (partidos, sindicatos, embajadas, gobiernos, municipios), o de las estructuras culturales (museos, galerías o centros culturales) no implica prescindir del análisis de las redes de actores relacionados con ellas. Alrededor de 3000 personas estuvieron vinculadas a las actividades del MIRSA, excluyendo a los visitantes de las exposiciones. ${ }^{8}$ En este sentido, si enumeramos las personas movilizadas en el MIRSA en comparación al Museo de la Solidaridad, "la solidaridad en la resistencia parecía ser un concepto aún más poderoso" como lo comenta Carla Macchiavello (2020, p. 11). Inspirándose de los trabajos de Howard Becker (2010), hemos destacados tres categorías de "mundos" interdependientes que posibilitaron el desarrollo del museo en el exilio (véase figura 1). Estas interrelaciones y cooperaciones entre mundos intelectuales, de las artes y de la política invitan a aunar las categorías tradicionales de los actores movilizados en las manifestaciones de solidaridad. Además, muchos actores pertenecían a diferentes

${ }^{7}$ Déclaration de l'Association française des critiques d'art section française de l'association internationale des critiques d'art. 28 de noviembre de 1973. Opus International, núm. 48, enero de 1974.

${ }^{8}$ Cifra aproximada actual de personas referenciadas en la base de datos de la autora, incluyendo a los actores, los más activos, así como los intermedios institucionales o los periodistas que escribieron sobre las exposiciones en la prensa. Los artistas representan la categoría de actores la más exhaustiva, con 823 donantes al mínimo (Zaldívar, 2017, p. 124). 
Figura 1. Sociología e interconexiones de los actores movilizados en el museo en el exilio

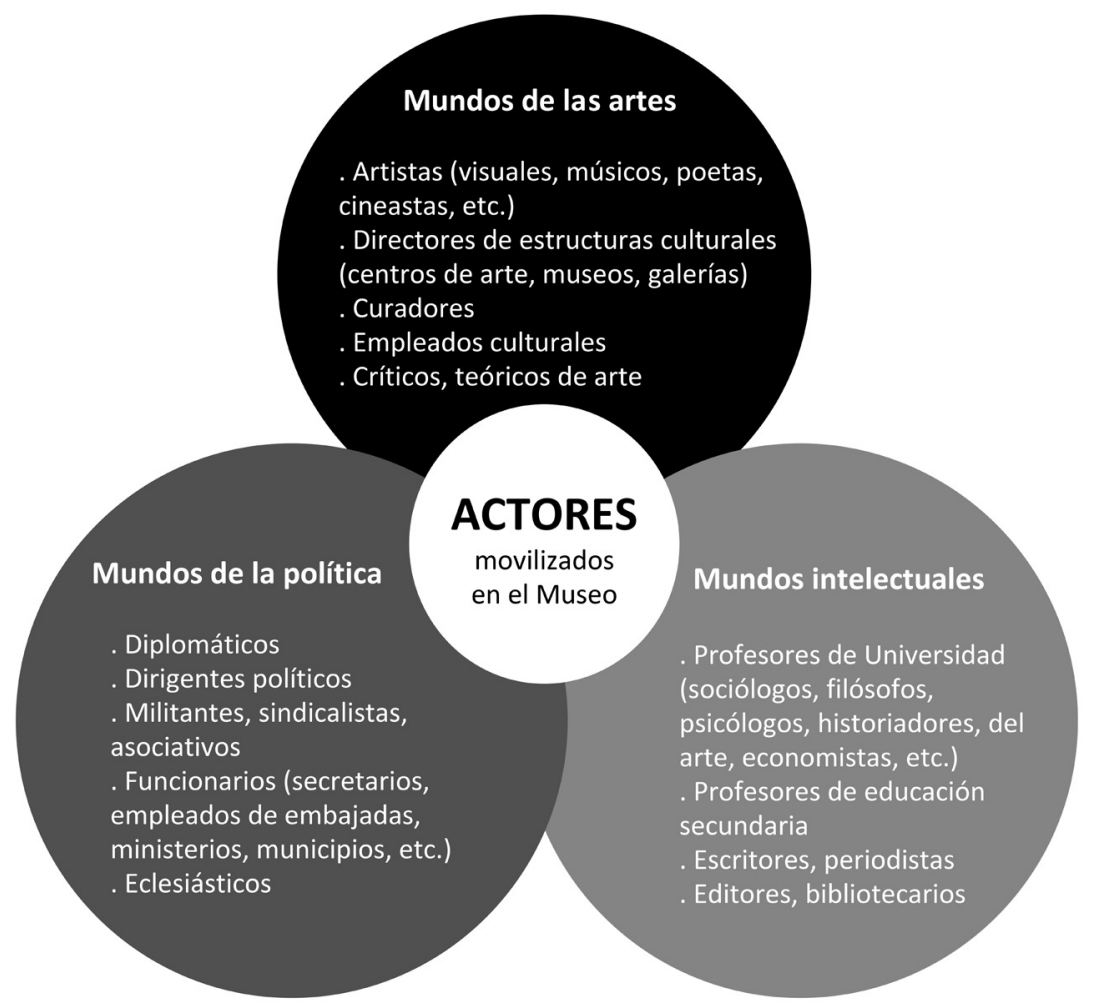

Fuente: elaboración propia.

grupos a la vez o tenían relaciones familiares, de proximidad y amistad con individuos de otras categorías. Si tomamos el ejemplo de Miria Contreras, el "alma" del Mirsa (Le Parc, 2017, p. 77) pertenecía a la vez al mundo de las artes como al mundo de la política. Ella fue consecutivamente galerista, secretaria del gabinete presidencial de Salvador Allende y empleada en el exilio de una compañía de aviación cubana (Havanatur) con sedes en París y La Habana. Ese cargo, como su proximidad con el gobierno revolucionario cubano, le daba una cierta libertad para viajar y cohesionar la gestión del MIRSA a través del mundo. 
A pesar de la multiplicidad y variedad de las muestras de solidaridad con Chile, y de los actores involucrados en ellas, todas se basaron en un consenso mayoritario en torno a la denuncia de los crímenes de la Junta militar chilena que fue favorecido y alimentado por la abundancia y la potencia de las imágenes con respecto a ello.

\section{IMAGINARIOS TRANSNACIONALES. SOPORTES VISUALES DE LA SOLIDARIDAD Y DE LA RESISTENCIA}

Existe una desconfianza en cuanto al uso del concepto "imaginario" que invita a repensar nuestra manera exclusivamente racional de concebir la historia a través de la preeminencia moderna del cogito cartesiano. Proponiendo una historia social de los usos y representaciones, los trabajos de Roger Chartier (1992) promovieron el concepto de "representación", término ya en uso en la época moderna, para dibujar un análisis cultural de las sociedades del antiguo régimen. Esta noción permitió superar la aparente contradicción entre la "objetividad de las estructuras" y la "subjetividad de las representaciones" (p. 56). Aunque fiel a esta tradición historiográfica que plantea la necesidad de estudiar las practicas y producciones culturales en relación con las divisiones del mundo social, nos parece más adecuado el concepto de "imaginario(s)" para estudiar las especificidades de los mundos sociales de los años 1960 y 1970 pertenecientes a las esferas políticas de las "izquierdas" a nivel internacional. Efectivamente, la noción de representaciones, si toma en cuenta los legados de la filosofía fenomenológica de Gaston Bachelard o Jean-Paul Sartre en los años 1930-1940, no hace caso de la filosofía de Cornelius Castoriadis. Su visión ontológica del mundo y de la creación, mediante su concepto de "imaginario colectivo", plantea una relación dialéctica entre el imaginario individual, como facultad humana psíquica abstracta, y las representaciones colectivas construidas que determinan la realidad social de una sociedad dada (Tomès, 2008, pp. 64-65). Es esta combinación entre racionalidad e irracionalidad, análisis materialista del mundo y aspiración utópica, la que puede dar más significado a la experiencia vital colectiva e individual de los actores que estamos estudiando, particularmente los que se sitúan en una perspectiva revolucionaria y que dedicaron su vida a su compromiso político.

Para comprender estos imaginarios en sus complejidades y no pensarlos únicamente de manera peyorativa como herramientas de propaganda, 
cabe destacar sus contextos de producción y las mentalidades de los agentes que las desarrollaron. Los regímenes de historicidad en los que se inscribieron los movimientos o procesos revolucionarios del siglo $\mathrm{xx}$, defendían una relación dialéctica, en un sentido marxista, entre pasado y futuro (Benjamin, 2013; Hartog, 2015; Traverso, 2016, pp. 200-201). El presente de lucha se concebía como una etapa de una larga tradición de rebeldía y experiencias revolucionarias que buscaba la justicia social, lo que le concedía legitimidad hasta la "victoria final". Los artistas comprometidos con los combates internacionalistas se inscribieron y participaron en la formación de imaginarios transnacionales y transhistóricos que servían a la difusión de los modelos políticos.

La victoria de la revolución cubana fue fundamental en el fortalecimiento de un sentimiento compartido de "comunidad imaginada" latinoamericana (Anderson, 2006; González Alemán y Palieraki, 2013) y más ampliamente tercermundista. El gobierno cubano, el Estado, el partido y las instituciones y actores artísticos y académicos orientados por aquellos, se dedicaron desde entonces, a través de sus encuentros políticos y culturales internacionales, a alimentar ese imaginario revolucionario transnacional (Mahler, 2018) que se destaca particularmente en las producciones de la OSPAAAL (Organización de Solidaridad de los Pueblos de África, Asia y América Latina) destinadas a ser publicadas en las revistas o los materiales militantes (afiches, folletos, etc.). La revista Tricontinental tenía una difusión masiva y global dentro de los movimientos de liberación y era utilizada como una fuente de inspiración para el desarrollo de lenguajes militantes, por ejemplo, por los colectivos de artistas izquierdistas en Europa alrededor de 1968 (Dossin, 2018). Los progresos técnicos y tecnológicos favorecieron la transnacionalización de las prácticas y de los modelos. Las artes visuales, desde el cine contrainformacional -Miguel Littín, Patricio Guzmán- (Cristiá, 2019), hasta las fotografías de prensa, los grabados o los afiches, desempeñaron un papel central en la difusión de estos discursos a nivel global y particularmente en los países de Asia, África y América Latina. Además, la movilidad de los artistas-militantes facilitó la circulación de estos imaginarios.

Las obras recogidas en el exilio deben ser analizadas entonces como "documentos históricos", fuentes primarias, capaces de develar informaciones porque muchas de ellas son los vehículos de los imaginarios sobre el Chile de la Unidad Popular y la dictadura, pero también sobre otros contextos político-históricos y geográficos que demuestran la circulación transnacional de los modelos del internacionalismo. 
Diversos temas se encuentran en los imaginarios de las colecciones del Museo de la Solidaridad y el MIRsA. La identidad latinoamericana, los héroes revolucionarios, el pueblo luchando, el pueblo trabajador, son frecuentemente representados a través de símbolos y estereotipos que favorecen un imaginario transnacional de la revolución, una visión binaria de un mundo dividido entre imperialismo y antiimperialismo, revolución y contrarrevolución. Así, el topos de la revolución mundial conjugado con la urgencia de la lucha favorecieron representaciones arquetípicas para facilitar la propagación de un lenguaje visual capaz de adaptarse fácilmente mediante códigos propios a cada contexto de lucha.

Benedict Anderson (2006), citando los trabajos de Eric Hobsbawm, ya resaltó la sustancia irremediablemente nacional de las revoluciones o movimientos de liberación de carácter marxista (pp. 2-3). Lejos de ser contradictorias, las tensiones existentes entre las reivindicaciones nacionales y las aspiraciones transnacionales de estas agrupaciones se explican por la voluntad de poner fin a la dependencia económica y cultural de los países del "tercer mundo" por parte de Estados Unidos o de otras potenciales coloniales o neocoloniales. El motivo de la correlación entre intereses estadunidenses y regímenes autoritarios latinoamericanos se encuentra frecuentemente en las colecciones. Ya en la caricatura de los inicios del siglo $\mathrm{xx}$, la metonimia del sombrero del Tío Sam sirvió para denunciar la intervención de Estados Unidos en la guerra de Independencia de Cuba contra España. Ese topos está todavía muy presente al momento de mostrar los intereses mortíferos de esta potencia extranjera en la región. Carlos Bernasconi, en su obra de 1976, pone ese accesorio (el sombrero) sobre la cabeza de un espantapájaros, cuyos brazos sostienen unos buitres caracterizados por los rostros de los dirigentes de la Junta chilena, tales como se ven en las fotografías oficiales del régimen (véase imagen 1 ).

Algunas obras fueron creadas precisamente para condenar el golpe de Estado y las violaciones orquestadas por la Junta militar en contra de los derechos humanos. Muchas obras proponen una identificación clara del "enemigo" contra el que hay que resistir. Ofrecen representaciones brutales de fascismos y contrarrevoluciones que reflejan la violencia de sistemas dictatoriales basados en la noción de "seguridad nacional" (Uruguay, Brasil, Bolivia, Chile, Argentina), persiguiendo una política de terror a través de las desapariciones, el internamiento y la tortura de enemigos políticos, y en las políticas imperialistas de Estados Unidos en América Latina. Para condenar estos regí- 


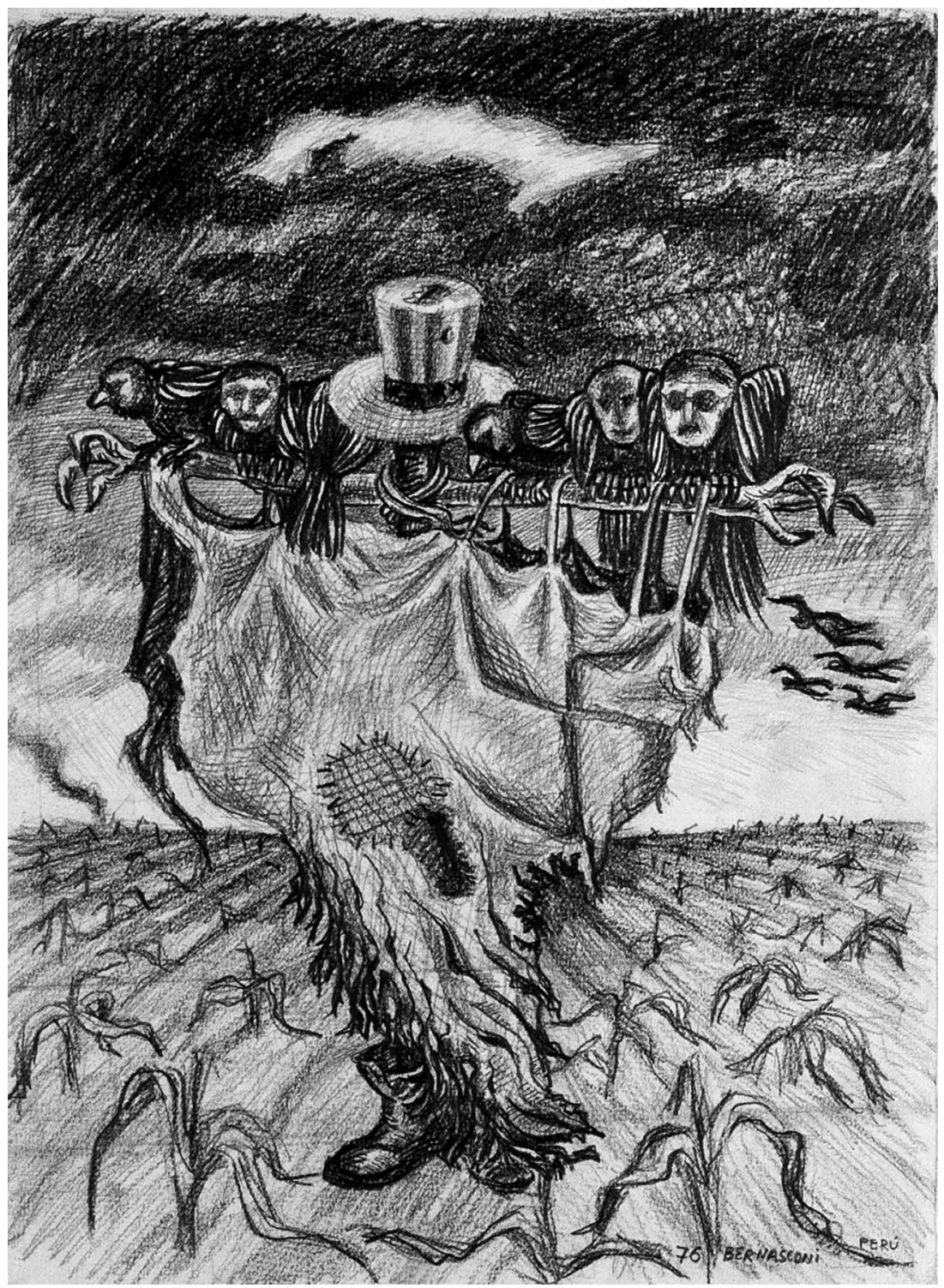

Imagen 1. Carlos Bernasconi, Sin título, 1976 Grafito sobre papel, 50 x $32.5 \mathrm{~cm}$. Donación del artista al Museo Internacional de la Resistencia Salvador Allende. Colección MssA. Archivo MSSA. 
menes, los artistas recurrieron con frecuencia a la iconografía de la muerte o de la guerra para que su mensaje fuese más explicito. El afiche producido por el catalán Josep Renau resume el imaginario macabro y sangriento que rodeaba a la junta militar chilena, como su carácter supuestamente antipatriótico (véase imagen 2).

Sin embargo, frente a esta violencia, las víctimas no son siempre representadas como pasivas. La resistencia es un tema recurrente en las obras que se encarna en tres tipologías: la resistencia personificada por héroes, la resistencia anónima y la resistencia colectiva encarnada en levantamientos de las masas. La figura de Salvador Allende, así como sus gafas, fueron iconografías privilegiadas por los artistas. El retrato del presidente difunto se encuentra en varias obras de la colección demostrando que la figura de Allende se convirtió en una verdadera efigie transnacional de la resistencia antifascista (véase imagen 3).

Al lado de un imaginario transnacional aparece un imaginario transhistórico de la lucha contra el "fascismo". Entre otros factores, ver las imágenes mediáticas de los soldados apuntando sus fusiles contra civiles desarmados, el bombardeo del palacio de La Moneda, o la quema de libros, recordaron a las memorias colectivas europeas oscuras páginas de la historia reciente que habían sido silenciadas durante décadas, y favorecieron la adhesión en Europa de la opinión pública a favor de la causa de los pueblos latinoamericanos y particularmente del pueblo chileno. En esta coyuntura, los artistas, principalmente los que vivían en las dos Europas, aprovecharon la historia reciente para hacer comparaciones entre, de un lado, los eventos trágicos de los años 1930-1940 o las dictaduras del sur que perduraron hasta la mitad de los años 1970 (Portugal, España, Grecia) y, del otro lado, los regímenes "fascistas" latinoamericanos, usando signos icónicos como la esvástica nazi, armas o cascos de soldados para alertar sobre la situación dramática de los pueblos del Cono Sur y ampliar las acciones de solidaridad. Un ejemplo elocuente es la obra Kultur, la destruction des livres au Chili (1973) de Joan Rabascall (véase imagen 4). El artista catalán reutilizó una fotografía famosa donde un militar chileno está quemando libros. La impresión de la palabra "KULTUR" en alemán en la parte inferior de la tela se refiere implícitamente a los "autos de fe" nazis.

Más que comparaciones fortuitas, algunos artistas se identificaron enteramente con la lucha del pueblo chileno haciéndola suya. Para ellos, no se trataba solamente de la lucha del pueblo chileno, sino de un combate permanente por la liberación de la humanidad que trascendía las épocas y las 


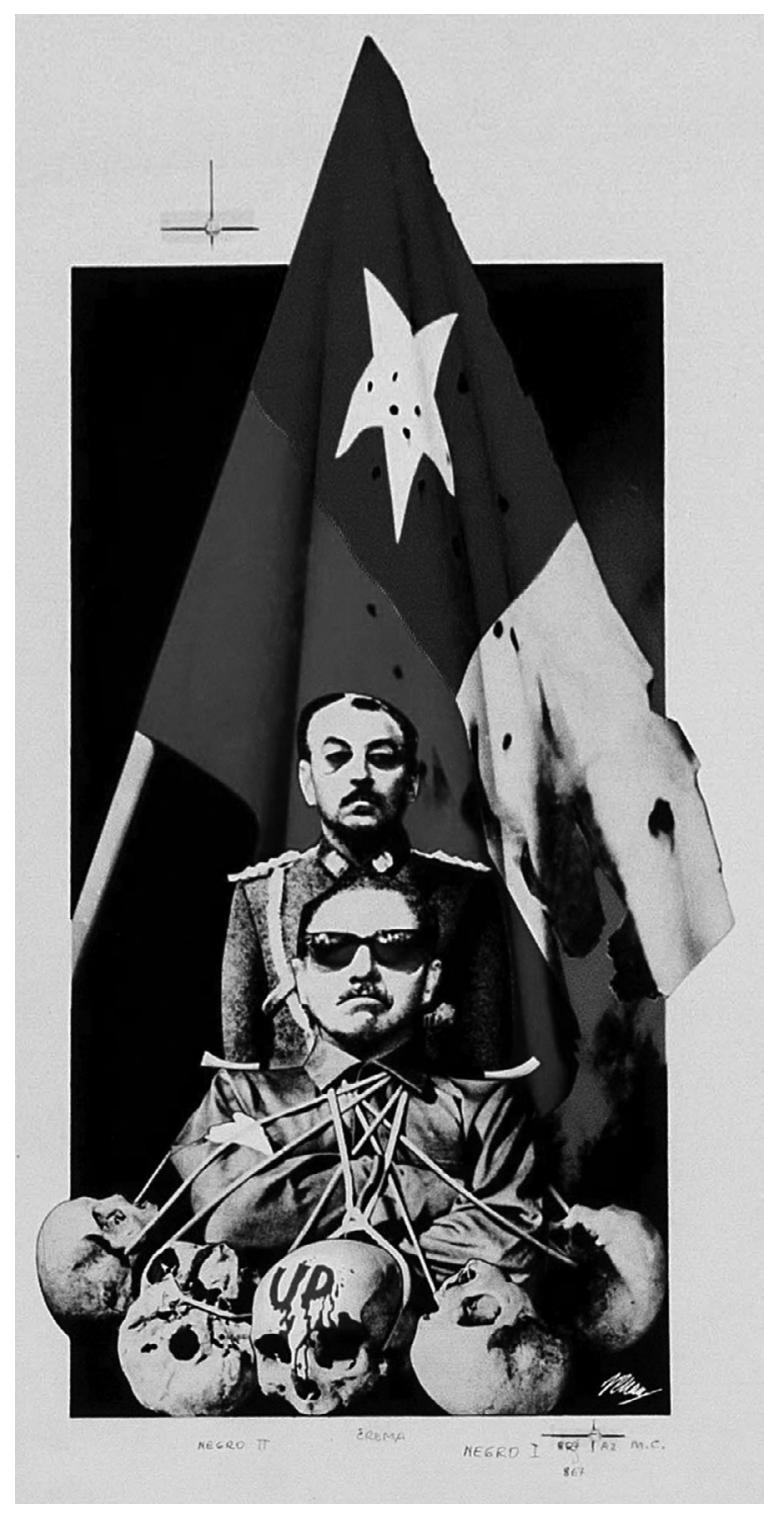

Imagen 2. Josep Renau, Proyecto para un afiche, 1978. Offset, 40.4 x $21.6 \mathrm{~cm}$. Donación del artista al Museo Internacional de la Resistencia Salvador Allende. Colección MssA. Archivo MSSA. 


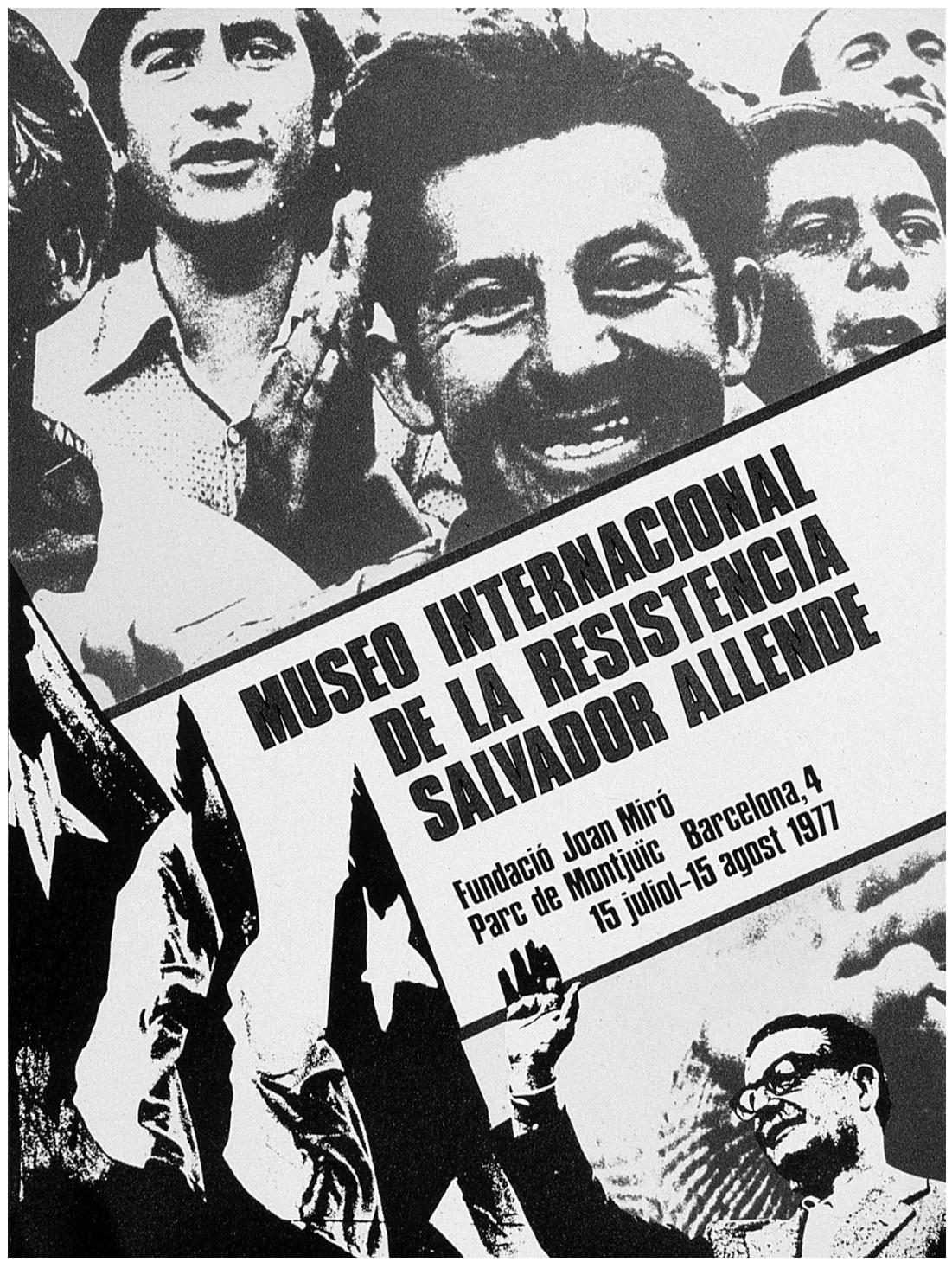

Imagen 3. Afiche de la exposición del MIRSA (15 de junio-15 de julio de 1977. Fundació Joan Miró, Barcelona). Archivo General de la Fundació Joan Miró, u. i. 135. 


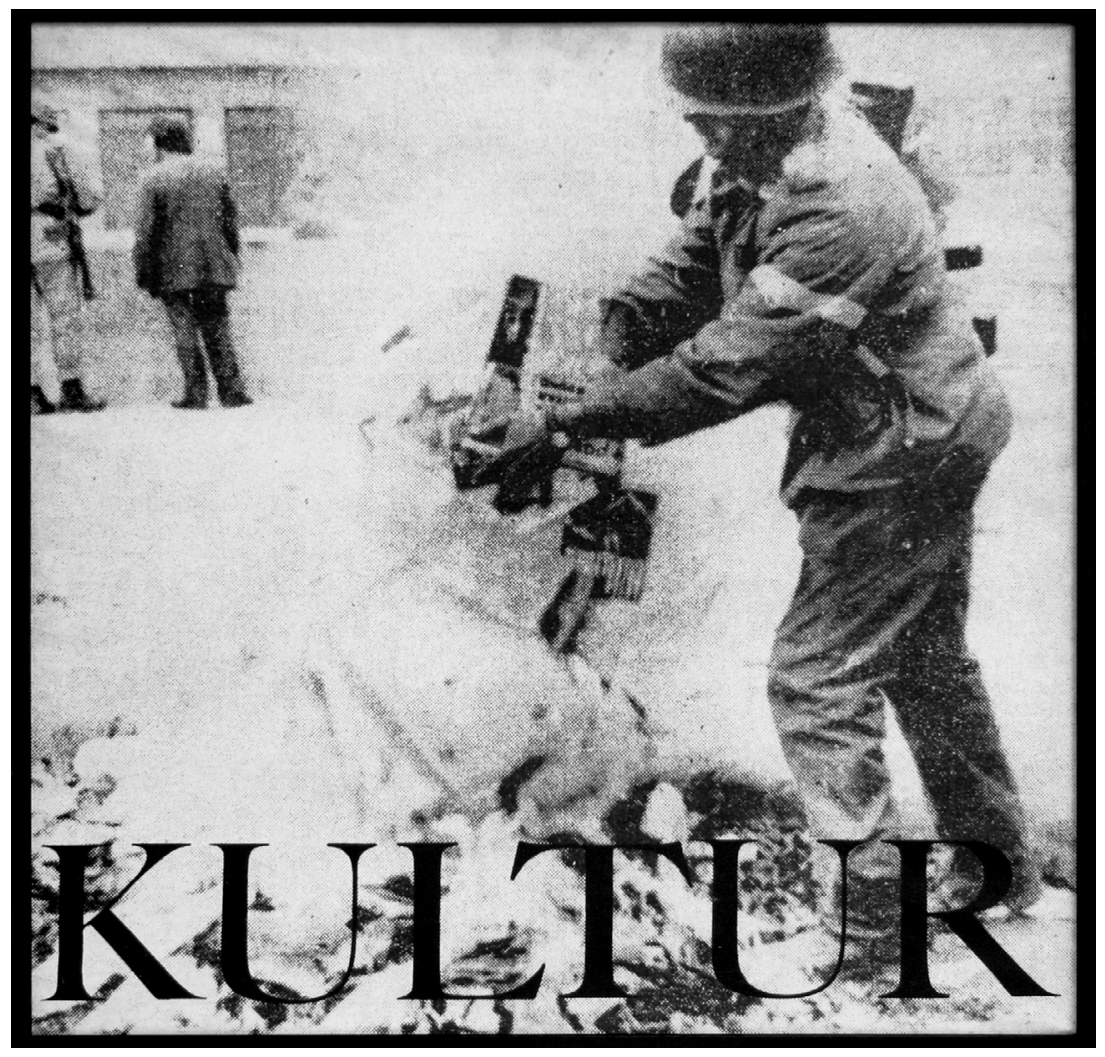

Imagen 4. Joan Rabascall (España, 1935). Kultur, la destruction des livres au Chili (Cultura, la destrucción de libros en Chile), 1973. Emulsión fotográfica sobre tela, $120 \times 120 \mathrm{~cm}$. Donación del artista al Museo Internacional de la Solidaridad Salvador Allende. Colección MSSA. Archivo MSSA.

fronteras. "La identificación con la fe de las víctimas y/o con la causa de los oponentes (proximidad ideológica) fue esencial para el establecimiento y el fortalecimiento de la acción solidaria" (Christiaens, Goddeeris y Rodríguez García, 2014, p. 14). La declaración del artista español Tony Gallardo, miembro del Partido Comunista de España, es particularmente reveladora de la continuidad existente entre todas estas luchas en el tiempo:

He luchado contra el imperialismo en la tierra americana. He sufrido en carne propia la represión. He entregado la parte más importante de mi vida a la 
lucha contra el franquismo. Por eso siento como propia la lucha del pueblo chileno por la libertad y me identifico con su dramática epopeya. Dono esta obra como homenaje a Salvador Allende, que supo encarnar con su sacrificio el ansia de emancipación de todos los pueblos de América sojuzgados por el imperialismo. ${ }^{9}$

Estratégicamente, las campañas de solidaridad pasaban entonces por la conformación de una cultura de la resistencia que tomaban prestados los símbolos de varias épocas y geografías para generalizar la denuncia, adaptarla a diferentes contextos de recepción y favorecer la identificación.

\section{EL RETORNO. CONCLUSIONES Y APERTURA}

Con el fin de la dictadura, las obras recolectadas en el exilio llegaron progresivamente a Chile para unirse a las que habían sido confiscadas por el régimen militar en 1973 o robadas por algunos dignatarios. La Fundación Salvador Allende, encabezada por Hortensia Bussi e Isabel Allende, respectivamente viuda e hija del expresidente, pasó a ser la institución tutelar del nuevo $\mathrm{Mu}$ seo de la Solidaridad Salvador Allende. El museo se inauguró en 1991 con gran pompa y circunstancia a través de una exposición organizada en el Museo de Bellas Artes a partir de los envíos de Francia, Suecia y España. De un museo itinerante pasó a convertirse en un museo en sí, con una sede propia, primero en calle Victoria Opazo, después en calle Herrera y, finalmente, en avenida República donde se encuentra ubicado en la actualidad.

La odisea de este museo nos narra una historia del exilio chileno que todavía queda por escribir en Chile (Toro, 2014). Si la inclusión de la realidad del exilio y su complejidad en el relato histórico de la dictadura militar lleva tiempo, el estudio del Museo Internacional de la Resistencia Salvador Allende da a conocer varios aspectos de los compromisos, las luchas y las producciones de la diáspora chilena, de sus diálogos con otras realidades políticas y artísticas nacionales, así como de las redes transnacionales que fomentó y que constituyeron luego los pilares de la diplomacia de los regimenes de la Concertación (Wright y Oñate Zúñiga, 2007). Más allá de una tradicional historia

${ }^{9}$ Ficha donación MIRsA de Tony Gallardo. 29 de junio de 1977. Fondo Colección. Serie Donaciones. e0269. MSSA, Santiago de Chile. 
de las elites políticas, nuestro enfoque valoriza la agencia de los intelectuales, de los artistas y de los actores de los "mundos del arte" en la creación de redes transnacionales y geografías alternativas (Barreiro López, 2019, p. 18), conjuntamente a la de los agentes políticos -militantes, cuadros, dirigentes o diplomáticos-, así como sus interrelaciones o interpenetraciones mutuas, en los niveles locales, nacionales, regionales e internacionales.

Por lo tanto, si bien Chile aprovechó la ola internacionalista de los años sesenta, el giro de la globalización neoliberal en los ochenta tuvo un fuerte impacto ideológico en las elites exiliadas, logrando deshacer progresivamente un modelo solidario y antifascista heredado de los años treinta y, particularmente, de las Brigadas Internacionales. Todavía falta interrogarse sobre las consecuencias del retorno de la diáspora en la reconfiguración del paisaje político e institucional chileno. Como Ulises volviendo a Ítaca, la realidad que acogió el nuevo Museo Salvador Allende era diferente de la que dejó saliendo al exilio. Vladimir Jankélévitch (1983) señala:

El viajero regresa a su punto de partida, ipero entretanto ha envejecido! [...] Si hubiera sido un simple viaje en el espacio, Ulises no se habría decepcionado; lo irremediable no es que el exiliado dejara su tierra natal: lo irremediable es que el exiliado dejara su tierra natal hace veinte años. Al exiliado le gustaría volver no sólo a su lugar de nacimiento sino también al joven que fue cuando vivía allí. [...] Ahora Ulises es otro Ulises, que encuentra otra Penélope... E Ítaca también es otra isla, en el mismo lugar, pero no en la misma fecha; es una patria de otro tiempo (Traducción mía, p. 300).

Esta tensión diacrónica entre los periodos de la Unidad Popular, el exilio y de la transición hacia la democracia, convierten a este museo en un electrón libre, a la vez inscrito en contextos nucleares particulares y en un objeto suelto, ambivalente y evolutivo, con varios proyectos que se suman, se complementan y se oponen en el tiempo y el espacio. ¿Qué hacer de esta coexistencia de memorias? ¿Cómo dar cuenta de esta multiplicidad de relatos que se entrecruzan o se combaten? Los acontecimientos actuales en Chile y las múltiples referencias a la experiencia de la Unidad Popular muestran que todavía falta un largo camino por recorrer para poner fin a los legados de la dictadura. Estas experiencias transnacionales que los investigadores están ayudando a (re)descubrir podrían ofrecer fuentes de inspiración para los combates presentes y futuros. 


\section{LISTA DE REFERENCIAS}

Anderson, B. (2006). Imagined communities. Reflections on the origin and spread of nationalism. Londres: Verso.

Barreiro López, P. (ed.). (2019). Atlántico frío. Historias transnacionales del arte y la política en los tiempos del telón de acero. Madrid: Brumaria.

Becker, H. S. (2010). Les mondes de l'art (trad. de J. Bouniort,). París: Flammarion.

Benjamin, W. (2013). Sur le concept d'histoire; suivi de Eduard Fuchs, le collectionneur et l'historien; et de Paris, la capitale du xixe siècle (trad. de O. Mannoni). París: Payot \& Rivages.

Bouamama, S. (2016). La Tricontinentale : Les peuples du Tiers-Monde à l'assaut du ciel. Ginebra: CETIM.

Camacho Padilla, F. (2011). Una vida para Chile: La solidaridad y la comunidad Chilena en Suecia 1970-2010. Estocolomo: Instituto de Estudios Latinoamericanos-Universidad de Estocolmo.

Castaneda, J. (1974). La Charte des droits et des devoirs économiques des États. Note sur son processus d'élaboration. En Annuaire français de droit international (vol. 20, pp. 31-56). París: CNRS.

Chartier, R. (1992). El mundo como representación. En El mundo como representación. Historia cultural: entre práctica y representación (pp. 45-62). Barcelona: Gedisa.

Christiaens, K., Goddeeris, I. y Rodríguez García, M. (eds.). (2014). European solidarity with Chile, 1970s-1980s. Frankfurt: Peter Lang.

Compagnon, O. y Moine, C. (eds.) (2015). Chili 1973, un événement mondial. Rennes: Presses Universitaires de Rennes.

Cristiá, M. (2019). Imágenes robadas a la represión chilena. Redes transnacionales de denuncia y cine contrainformacional durante la dictadura de Augusto Pinochet. Historia y Sociedad, 37, 173-200. DoI: https://doi.org/10.15446/hys.n37.74268

Devin, G. (ed.). (2004). Les solidarités transnationales [Actes du troisième colloque de la Section d'études internationales de l'Association française de science politique, Paris, 21-22 octobre 2003]. París: L'Harmattan.

Dossin, C. (2018). The Brush and the Kalashnikov: The political vision of the jeune peinture from Paris to Beirut (pp. 279-296). En K. Khouri y R. Salti (eds.), Past Disquiet: Artists, international solidarity, and museums-in-exile. Varsovia: Muzeum Sztuki Nowoczesnej.

Fermandois, J. (1985). Chile y el mundo, 1970-1973: La política exterior del gobierno de la Unidad Popular y el sistema internacional. Santiago de Chile: Ediciones Universidad Católica de Chile. 
Fox, C. F. (2016). Arte panamericano. Políticas culturales y guerra fría (trad. de S. Jatz Rawicz). Santiago de Chile: Ediciones Metales Pesados.

Garza, A. de la y Vargas Santiago, L. (coords.). (2016). A los artistas del mundo... Museo de la Solidaridad Salvador Allende, México/Chile 1971-1977, [Exposición del 27 de agosto al 7 de noviembre de 2016, MUAC, Universidad Nacional Autónoma de México, Ciudad de México; y del 15 de octubre de 2016 al 22 de enero de 2017, MSSA, Santiago de Chile]. México/Barcelona: Editorial RM.

González Alemán, M. y Palieraki, E. (eds.). (2013). Revoluciones imaginadas. Itineriarios de la idea revolucionaria en América Latina contemporánea. Santiago de Chile: RIL.

Harmer, T. (2011). Allende's Chile and the inter-American cold war. Chapel Hill; The University of North Carolina Press.

Harmer, T. y Riquelme Segovia, A. (eds.). (2014). Chile y la guerra fría global. Santiago de Chile: RIL.

Hartog, F. (2015). Régimes d'historicité. Présentisme et expériences du temps. París: Points. Iriye, A. (1991). Culture and international history. En M. J. Hogan y T. G. Paterson (eds.), Explaining the history of American foreign relations (pp. 241-256). Cambridge: Cambridge University Press.

Jankélévitch, V. (1983). L’irréversible et la nostalgie. París: Flammarion.

Joyeux-Prunel, B. (ed.) (2017). Art history and the global challenge. Artl@s Bulletin. 6(1).

Khouri, K. y Salti, R. (eds.) (2018). Past disquiet: Artists, international solidarity, and museums-in-exile. Varsovia: Muzeum Sztuki Nowoczesnej.

Lebeau, É. (2016). Le Musée International de la Résistance Salvador Allende en France (1975-1991). L'Odyssée d'une collection d'art contemporain en exil (Tesis de maestría inédita). Universidad de Toulouse 2 Jean Jaurès, Francia.

Lebeau, É. (2018). El Museo Internacional de la Resistencia Salvador Allende (19751990). Transnacionalización del Museo de la Solidaridad en exilio. Ponencia presentada en el $56^{\circ}$ Congreso Internacional de Americanistas. Salamanca, España.

Le Parc, J. (2017). Testimonio para el catálogo razonado sobre el Museo Internacional de la Resistencia Salvador Allende (pp. 76-77). En Zaldívar, C. (ed.) (2017). El Museo Internacional de la Resistencia Salvador Allende. Catálogo razonado. Santiago de Chile: Museo de la Solidaridad Salvador Allende.

Levi, G. (2018). Microhistoria e historia global. Historia Crítica, 69, 21-35. DoI: https:// doi.org/10.7440/histcrit69.2018.02

Macchiavello, C. (2017). Fibras resistentes: sobre el/los/algunos Museos de la Resistencia (pp. 28-72). En C. Zaldívar (ed.), El Museo Internacional de la Resistencia 
Salvador Allende. Catálogo razonado. Santiago de Chile: Museo de la Solidaridad Salvador Allende.

Macchiavello, C. (2020). Weaving forms of resistance: The Museo de la Solidaridad and The Museo Internacional de la Resistencia Salvador Allende. Arts, 9(1), 12. DOI: https://doi.org/10.3390/arts9010012

Macchiavello, C. y Suárez, S. J. (2015). Solidaridad, práctica, redes y revolución: una crónica breve del surgimiento y oclusión del meridiano Chile-Cuba, en el ámbito del arte latinoamericano. En M. C. Bernal Bermúdez (ed.). Redes intelectuales. Arte y política en América Latina. Bogotá: Facultad de Artes y Humanidades-Universidad de los Andes.

Mahler, A. G. (2018). From the Tricontinental to the global South: Race, radicalism, and transnational solidarity. Durham: Duke University Press.

Matul, K. (2018). "Art instead of politics": Polish artists "in solidarity" with Palestine and Chile in the 1970s and 1980s (pp. 207-219). En K. Khouri y R. Salti (eds.), Past Disquiet: Artists, international solidarity, and museums-in-exile. Varsovia: Muzeum Sztuki Nowoczesnej.

McMahon, R. J. (ed.) (2013). The cold war in the third world. Oxford: Oxford University Press.

Miranda, C. (2013). Gesto político y fraterno. En C. Zaldívar (ed.), Museo de la Solidaridad Chile: fraternidad, arte y política 1971-1973. Donación de los artistas al Gobierno Popular (pp. 108-134). Santiago de Chile: Museo de la Solidaridad Salvador Allende.

Montupil Inaipil, F. (1993). Exilio, derechos humanos y democracia. El exilio chileno en Europa. Santiago de Chile: Servicios Gráficos Caupolicán.

Norambuena, C. (2008). El exilio chileno: río profundo de la cultura iberoamericana. Sociohistórica, 23-24, 163-195.

Pedemonte, R. (2012). La guerre froide culturelle en Amérique latine : Les espaces d'amitié et d'échange avec l'Union soviétique. Cahiers des Amériques: Figure de l'Entre. Amitiés: Le cas des mondes Américains (vol. 2, pp. 137-152). La Rochelle: La Promenade.

Piškur, B. (2016). Solidarity in arts and culture. Some cases from the Non-Aligned Movement. L'Internationale. Recuperado de https://www.internationaleonline. org/research/alter_institutionality/78_solidarity_in_arts_and_culture_some_ cases_from_the_non_aligned_movement

Preda, C. (2020). The Chilean Museum of Solidarity and transregional links with Romania during the cold war. Online Journal Modelling the New Europe, 32, 35-57. 
Prognon, N. (2013a). Producción cultural de los exiliados chilenos en Francia: la construcción de una indispensable memoria de la Unidad Popular para la democracia chilena. En B. Santini y L. Boussard (eds.). Chile en el siglo XXI: ¿nuevos recorridos artísticos, nuevos caminos históricos? (pp. 15-32). Santiago de Chile: Piso Diez Ediciones.

Prognon, N. (2013b). L'exil chilien en France entre mobilités transnationales et échanges. Amnis. Revue de Civilisation Contemporaine Europes/Amériques, 12. Dor: https:// doi.org/10.4000/amnis.1931

Rojas Mira, C. (2013). El exilio político chileno: La casa de Chile en México (1970-1993), una experiencia singular (Tesis de doctorado inédita). Universidad de Santiago de Chile, Chile.

Rojas Mira, C. y Santoni, A. (2013). Geografía política del exilio chileno: Los diferentes rostros de la solidaridad. Perfiles Latinoamericanos, 21, 123-142. DoI: https://doi. org/10.18504/pl2141-123-2013

Rojas Mix, M. y Juan, A. de (1971). Chile, artes plásticas. Exposición de La Habana 1971 (chileno-cubana). Casa de las Américas, 69, 187-191.

Saunier, P.-Y. (2013). Transnational history. Houndmills: Palgrave MacMillan.

Shaw, T. (2001). The politics of cold war culture. Journal of Cold War Studies, 3(3), 59-76.

Sirinelli, J.-F. (2004). Histoire culturelle des relations internationales: Carrefour méthodologique: xxe siècle. París: D. Rolland.

Stites Mor, J. (ed.) (2013). Human rights and transnational solidarity in cold war Latin America. Madison: The University of Wisconsin Press.

Stonor Saunders, F. (2013). The cultural cold war. The cIA and the world of arts and letters. Nueva York: New Press.

Tomès, A. (2008). Introduction à la pensée de Castoriadis. En C. Castoriadis, L'imaginaire comme tel (pp. 11-87) (texto editado y comentado por A. Tomès). París: Hermann.

Toro, B. (2014). Entre histoire et mémoire. Le Musée de la mémoire de Santiago du Chili. En M. Poinsot y B. Toro (eds.), L'exil chilien en France (pp. 173-175). Hommes $\mathcal{E}$ migrations, 1305. París: Musée de l'Histoire de l'Immigration.

Traverso, E. (2016). Mélancolie de gauche: La force d'une tradition cachée (XIXe-XxIe siècle). París: La Découverte.

Unidad Popular (ed.) (1970). Programa básico de gobierno de la Unidad Popular. Candidatura presidencial de Salvador Allende. Santiago de Chile: Instituto Geográfico Militar. 
Westad, O. A. (2007). La guerre froide globale: le tiers-monde, les États-Unis et l'URSS, 1945-1991 (trad. de C. Jeanmougin). París: Payot.

Wright, T. C. y Oñate Zúñiga, R. (2007). Chilean political exile. Latin American Perspectives, 34(4), 31-49. DoI: https://doi.org/10.1177/0094582X07302902

Yasky, C. y Zaldívar, C. (2018). An Atypical Museum: The Museo de la Solidaridad Salvador Allende (pp. 299-315). En K. Khouri y R. Salti (eds.), Past Disquiet: Artists, international solidarity, and museums-in-exile. Varsovia: Muzeum Sztuki Nowoczesnej.

Zaldívar, C. (1991). Museo de la Solidaridad (Tesis de licenciatura inédita). Universidad de Chile, Chile.

Zaldívar, C. (ed.). (2017). El Museo Internacional de la Resistencia Salvador Allende. Catálogo razonado. Santiago de Chile: Museo de la Solidaridad Salvador Allende. 